\title{
Sobre a originalidade de Edith Stein: o papel da distinção entre Körper (corpo físico) e Leib (corpo "vivo") para a empatia e a constituição do eu
}

\author{
On Edith Stein's originality: the role played by the distinction \\ between Körper (physical body) and Leib (lived body) in both \\ empathy and the constitution of the self
}

\section{Juliana Missaggia*}

Universidade Federal de Santa Maria, Santa Maria, RS, Brasil

\section{Resumo}

O objetivo central do artigo é analisar a originalidade e o caráter precursor da obra de Edith Stein no que diz respeito a conceitos hoje clássicos no contexto dos estudos de fenomenologia, como corpo e empatia, e sua importância para a constituição da noção de eu. Mais precisamente, interessa-me analisar determinadas distinções conceituais, como o caráter dual do conceito de corpo desenvolvido pela filósofa, para com isso demonstrar sua importância para os desdobramentos das noções de empatia e subjetividade. A proposta interpretativa que guia essa exposição envolve a compreensão de que há, ao menos nessa fase do pensamento de Stein, uma primazia e centralidade do conceito de 
corpo (sobretudo entendido como Leib) para o estabelecimento dos conceitos de empatia e eu, o que é feito de modo distinto e original em relação aos trabalhos de Husserl. Para demonstrar tal interpretação, parto de uma exposição comparativa entre os dois autores e de uma análise mais detalhada dos conceitos pertinentes ao tema em Zum Problem der Einfühlung, obra clássica de Edith Stein.

Palavras-chave: Edith Stein. Fenomenologia. Corpo. Empatia. Eu.

\section{Abstract}

This article is chiefly aimed at analyzing Edith Stein's pioneering originality regarding concepts such as those of body and empathy —now acknowledged as representative notions in the field of phenomenological studies - and their significance to the making of the notion of self. Specifically, I analyze certain conceptual distinctions (such as the twofold character of Stein's concept of body) in order to show how said distinctions affect the notions of empathy and subjectivity in their implications. The reading that guides my exposition involves the following posit: at least in this stage of Stein's thought, the concept of body (especially when meant as Leib) takes precedency over the others and is, in this manner, the key to determine the concepts of empathy and self. Her argument unfolds in an original fashion, as it distinguishes itself from those in Husserl's writings. To substantiate this latter assessment, I compare both authors, further examining the relevant concepts presented in Zum Problem der Einfühlung, Edith Stein's classic work.

Keywords: Edith Stein. Phenomenology. Body. Empathy. Self.

\section{Considerações introdutórias: Körper e Leib no contexto de Zum Problem der Einfühlung e algumas dificuldades metodológicas}

A importante obra de Edith Stein, Zum Problem der Einfühlung ${ }^{1}$, surge a partir de sua tese de doutorado, redigida sob a orientação de

\footnotetext{
Sobre o problema da empatia, ainda sem versão em língua portuguesa. Cito a partir da edição de 2008, mencionada nas referências bibliográficas. As traduções citadas são de minha responsabilidade.
} 
Edmund Husserl e defendida em 1916, apenas um ano antes de sua publicação como livro. Hoje é sabido que, embora considerado um trabalho extremamente bem-sucedido já no contexto de seu surgimento, foram necessários muitos anos para que as pioneiras análises de Stein, em parte precursoras de temas depois estimados pela tradição fenomenológica, fossem investigadas com a merecida atenção.

O objetivo central dessa exposição é desenvolver algumas dessas questões ligadas a conceitos hoje clássicos no contexto dos estudos de fenomenologia, como corpo e empatia, a partir das considerações de Stein. Mais precisamente, interessa-me analisar determinadas distinções conceituais - como o caráter dual do conceito de corpo desenvolvido pela filósofa - para com isso demonstrar sua importância para os desdobramentos das noções de empatia e eu. A proposta interpretativa que guia essa exposição envolve a compreensão de que há, ao menos nessa fase do pensamento de Stein, uma primazia e centralidade do conceito de corpo (sobretudo entendido como Leib) para o estabelecimento dos conceitos de empatia e subjetividade. Tal preeminência da corporeidade enquanto "corpo vivo" representaria uma diferença significativa em relação a outras análises fenomenológicas, inclusive em relação às obras de Husserl, o que demonstra a originalidade do trabalho de Stein.

Na direção dessa interpretação, é interessante sublinhar o adendo de Stein no prólogo de Zum Problem der Einfühlung (doravante, ZPE), segundo o qual não efetuaria maiores correções no texto da tese para não acabar por meramente reproduzir o pensamento de seu professor, reconhecendo que no caso de seu texto de doutoramento ainda se poderia falar em "trabalho próprio", talvez ao contrário, segundo ela, de seus escritos imediatamente posteriores, já com caráter explicitamente husserlianos (ZPE, p. v-vi). Independentemente de possíveis exageros de gratidão por parte do reconhecimento de Stein sobre a influência de Husserl em seu pensamento, gostaria também de reforçar, com o objetivo principal de esclarecer a originalidade da filósofa, algumas distinções significativas entre os tratamentos conceituais das noções de corpo e empatia entre os dois autores, o que também ajudará a explicitar a abordagem steiniana. 
A primeira coisa a ser observada é que devemos entender o conceito de empatia no sentido filosófico adequado ao contexto da obra. Não se trata, como sabemos, da mesma definição da palavra em seu uso cotidiano, mas sim de um sentido com outra abrangência e com um tratamento específico ao interesse fenomenológico. Para Stein, portanto, Einfühlung tem um "sentido definido de maneira precisa enquanto experiência da consciência alheia" (ZPE, p. 24). Não é o caso, portanto, de referir apenas a atos empáticos no sentido de "se colocar no lugar" dos demais, ou de compreender os sentimentos, ideias e desejos de outra pessoa, mas sim, em geral, de ter vivência de outras consciências. Manifestações mais pontuais da experiência de empatia - como a compreensão de aspectos emocionais alheios - também podem ser eventualmente objeto de análise fenomenológica, mas não é esse uso específico aquele utilizado por Stein.

No contexto de ZPE, como a filósofa esclarece, a questão da empatia é analisada dentro do escopo do método fenomenológico e, portanto, dentro dos limites impostos pela redução fenomenológica (ZPE, p. 11). Como sabemos, a redução envolve a suspensão de juízo sobre a existência dos objetos do mundo e a atitude de passar a atenção dos objetos de nossa experiência para o modo como eles são experienciados. Uma das implicações de tal posição envolve a impossibilidade de analisar o fenômeno a ser descrito a partir de sua (suposta) existência "efetiva" (existência em uma realidade transcendente à consciência) e, evidentemente, também a inviabilidade de sua investigação a partir de outras ciências.

Uma das dificuldades imediatas em relação a tal estrutura e princípios do método de redução - a qual, aliás, também aparece explicitamente em Husserl - é como analisar determinados aspectos dos fenômenos, como sua dimensão física, se todo o interesse sobre sua realidade enquanto objeto transcendente é mantido em suspenso e a investigação se volta para sua aparição à consciência interna do eu. Em outras palavras, e considerando em particular as noções de corpo e empatia, surge a questão de como analisar fenomenologicamente conteúdos que parecem envolver justamente a realidade exterior e o pressuposto de existência efetiva de outras consciências. Como reconhece a 
filósofa: "todo o mundo circundante, tanto físico como psicológico, os corpos, assim como as almas humanas e animais (incluindo a pessoa psicofísica do próprio investigador), está sujeito à exclusão ou redução" (ZPE, p. 11).

A proposta de Stein segue, em grande medida, a estrutura clássica proposta por Husserl: embora se suspenda o juízo sobre a existência efetiva do mundo, permanecemos com toda a experiência "intacta" do mundo enquanto fenômeno para a consciência, de modo que nada é perdido na investigação. E é justamente a partir dessa análise que, no jargão fenomenológico, dá um "passo atrás" em direção à descrição cuidadosa das aparições que podemos verificar uma distinção filosoficamente relevante no que diz respeito aos fenômenos corpóreos: no interior de nossa experiência, destaca-se a diferença fundamental entre a percepção de meros corpos físicos, enquanto objetos "inanimados" do mundo, e os "corpos vivos" dotados de vontade e vivências. Nas palavras de Stein:

Poderíamos partir do fenômeno concreto, completo, que temos diante de nós no mundo da experiência, do fenômeno de um indivíduo psicofísico que se distingue nitidamente de uma coisa física. Esse não se dá como corpo físico (Körper), mas sim como corpo vivo (Leib) senciente ao qual pertence um eu, um eu que percebe, pensa, sente, quer, e cujo corpo vivo não está meramente incorporado no meu mundo fenomenal, mas sim é o próprio centro de orientação de tal mundo [...]. E também poderíamos investigar como tudo o que nos aparece além do mero corpo físico dado na percepção externa se constitui na consciência (ZPE, p. 13).

Assim, Körper diz respeito aos aspectos estritamente materiais e físicos do corpo, daquilo que ele tem em comum com todos os objetos do mundo, abstraindo, portanto, da sua conexão com uma consciência. Leib, por outro lado, é o corpo enquanto algo vivo, animado por uma "alma" e que envolve todos os aspectos psicológicos da consciência. Conforme aponta Natalie Depraz, a diferença entre as duas expressões pode ser explicada em termos etimológicos: lîp, no alemão antigo, possuía um sentido que abrangia tanto "corpo" como, em geral, "vida" (que viria a se tornar "Leben"). "Corpo" no sentido de "Leib", portanto, guarda essa conexão com a ideia de vida, de algo que não é mera coisa 
material inanimada. Körper, por outro lado, é apenas a versão germânica da palavra latina corpus, e remete à concepção de corpo apenas enquanto objeto físico (DEPRAZ, 1995, p. 344).

Como já é possível antever, a importância imediata de tal distinção para a análise do fenômeno da empatia é bastante direta: compreender os demais em empatia genuína implicará, justamente, concebê-los não apenas enquanto meros corpos físicos, mas como corpos vivos. Porém, para além de tal implicação, como veremos em mais detalhes adiante, há uma série de consequências - como a influência das vivências empáticas para a própria constituição do eu - as quais envolvem inclusive uma ampliação significativa do conceito de empatia, que ganha maior riqueza e complexidade em comparação com as análises de Husserl. Para demonstrar tal interpretação, portanto, parto de uma breve análise comparativa entre as concepções de corporeidade dos dois filósofos, para, em seguida, desenvolver os conceitos pertinentes a partir dos argumentos apresentados por Stein em Zum Problem der Einfühlung ${ }^{2}$.

\section{A originalidade de Edith Stein em relação à distinção Körper/Leib: uma comparação com Husserl}

Como sabemos, também na obra de Husserl a distinção entre Körper e Leib é importante. Tal diferenciação conceitual, embora venha a aparecer de maneira mais explícita e detalhada somente em Die Krisis der europäischen Wissenschaften und die transzendentale Phänomenologie (doravante Krisis), já é antevista em Ideen zu einer reinen Phänomenologie und phänomenologischen Philosophie. Zweites Buch. Phänomenologische Untersuchungen zur Konstitution (Ideen II), mas há razões para crer que os conceitos ainda não estavam plenamente desenvolvidos nesse primeiro momento. O que demonstra isso é, principalmente, o fato de Husserl utilizar indiscriminadamente a expressão "Leib" para se referir tanto ao corpo enquanto coisa física quanto ao corpo vivo em Ideen II. O filósofo

\footnotetext{
2 Para uma análise que envolva a comparação das considerações de Stein com outros autores ligados à fenomenologia, além de Husserl, ver Szanto e Jardine (2017).
} 
por vezes utiliza "Körper" nessa obra, mas geralmente para tratar dos meros objetos físicos e não do corpo em si. Outra questão é que, embora haja muitas considerações sobre as características e peculiaridades do corpo vivo, a ênfase de comparação não é com o nosso corpo enquanto coisa física, mas sobretudo a diferença entre corpo vivo e, em geral, todos os demais objetos do mundo.

Assim, Husserl explicita em Ideen II que embora o corpo seja um objeto como os demais, sujeito às mesmas leis e propriedades, ele possui características que o tornam distinto dos demais corpos com os quais nos relacionamos. Nosso próprio corpo pode, assim como todos os objetos, ser por nós visto e tocado. Mas o fato de nosso corpo ser o "portador das sensações" faz com que, ao ser tocado, ele também perceba o toque: o corpo é, de fato, simultaneamente ativo e passivo na faculdade tátil. Podemos, é claro, dizer que dois objetos físicos "se tocam" - "a cortina toca a parede", por exemplo - , mas nesse "tocar" nunca estamos nos referimos à mesma coisa que ocorre no caso do corpo vivo, que toca e é tocado. E assim também com as demais faculdades: nosso corpo pode, como qualquer objeto, ser visto, mas ele é também, ao mesmo tempo, o corpo que vể $\hat{\mathrm{C}}^{3}$ Assim, portanto, "meu corpo, na interação física com outras coisas materiais, envolve [...] não apenas a experiência de uma ocorrência física, [...] mas também a experiência de uma ocorrência especificamente corpórea do tipo que chamamos sensível". Tal tipo de ocorrência é o que falta às "meras coisas materiais" (HUSSERL, Ideen II, p. 146) ${ }^{4}$.

Também Stein procura diferenciar, em sua análise do corpo vivo, as peculiaridades no que diz respeito às sensações. Mas sua reflexão não envolve apenas uma comparação com os objetos em geral ou, nos termos husserlianos, as meras coisas materiais. A filósofa quer indicar,

3 Husserl generaliza, obviamente, para além dos casos particulares de um corpo humano que não possui alguma das faculdades. Cabe reforçar, também, que o filósofo explicita as diferenças entre os sentidos, como no caso da visão e do tato (ver HUSSERL, Ideen II, §37).

4 Para a citação das obras de Husserl utilizo, geralmente, o nome reduzido do livro ("Krisis", por exemplo), seguido da paginação no original e, quando disponível, da página correspondente na tradução em língua portuguesa, a qual cito. Eventualmente altero a tradução, casos nos quais acrescento "t.a.", "tradução alterada". Nas obras utilizadas para as quais não há tradução em nosso idioma, a tradução citada é de minha responsabilidade. 
justamente, a distinção interna ao conceito de corpo: a diferença entre entender a corporeidade em termos de corpo vivo e corpo físico tem implicações diretas para a investigação do fenômeno da vivência das faculdades sensíveis. Como explicita Edith Stein, a esse respeito: “[...] meu corpo vivo se constitui de uma maneira dupla, enquanto corpo vivo [Leib] senciente (percebido corporalmente) e enquanto corpo físico [Körper] do mundo externo percebido externamente, e nessa dupla apresentação é vivenciado como o mesmo [...]" (ZPE, p. 57).

Essa constituição dupla do corpo implica que embora possamos em teoria abstrair da sensação enquanto vivenciada no corpo vivo e percebê-lo apenas enquanto corpo físico, ou seja, enquanto objeto "externo", tal análise é em certo sentido artificial, pois é impossível abrir mão da faculdade senciente de nosso próprio corpo. Assim, ainda que possamos conceber uma reflexão intelectual que imagine o próprio corpo desde fora, enquanto Körper, isso não é possível enquanto vivência que concretamente suprima as sensações e a perspectiva desde dentro, inerente à vivência do corpo vivo. Em outras palavras, "os laços que nos unem a ele [ao corpo vivo] são indissolúveis" (ZPE, p. 62).

É importante observar aqui, no entanto, que Stein deixa claro desde a apresentação da distinção que, apesar da maneira "dupla" pela qual o corpo se apresenta na reflexão fenomenológica, ele é vivenciado como o mesmo. Não há, portanto, uma real duplicidade no que diz respeito à própria experiência, como se em determinado momento tivesse alguma vivência real de meu corpo enquanto mero corpo físico, enquanto Körper, mas sim que posso assim concebê-lo na reflexão fenomenológica, sendo por isso estabelecida essa duplicidade na descrição do fenômeno. Aliás, como será explicitado adiante, no caso das reflexões de Stein, a empatia tem um papel fundamental no estabelecimento desse caráter dual da experiência corpórea.

Voltando às análises husserlianas, outra característica fundamental e diferenciadora do corpo vivo em relação aos meros objetos é que ele é "um órgão de vontade, o único objeto que, pela vontade do ego, é imediata e espontaneamente movível e é um meio para produzir um movimento, por sua mediação espontânea, em outras coisas" (HUSSERL, Ideen II, §38, p. 152). Assim, embora os objetos em geral sejam potencialmente móveis, 
somente um corpo vivo se move por livre vontade, utilizando-se dessa faculdade para também dar movimento a outros corpos, não animados. Note-se que o ponto aqui é justamente a capacidade de movimento autônomo livre do corpo vivo, pois outros objetos - mecânicos, por exemplo - podem ser programados para gerar movimento a partir de si mesmos, mas não de maneira independente como o corpo vivo.

Nosso corpo está, além disso, envolvido como portador de outros modos de sensações, de um tipo de "objetividade superior", como no caso dos sentimentos, das sensações de prazer e dor, de bem ou mal-estar, etc., as quais permeiam as formas primárias de sensação. Dessa maneira, uma determinada sensação como sentir frio, por exemplo, pode ser acompanhada de um sentimento de desconforto. O corpo vivo, enquanto território de todos esses complexos integrados de sensações, é vivenciado por cada um como "seu corpo particular", enquanto "uma objetividade subjetiva distinta do corpo enquanto mera coisa material"5 (HUSSERL, Ideen II, p. 146). Isso quer dizer, portanto, que a experiência concreta de ter um corpo e perceber as coisas do mundo por seu intermédio envolve diversas sensações integradas, aos quais se unificam na identificação de si com seu corpo vivo próprio.

É importante observar, também, que Husserl reconhece que os momentos e tipos de sensações do corpo são distinguíveis apenas por abstração a partir de sua experiência, pois a maneira como vivenciamos todos esses momentos se dá de modo unificado: a sensação de muito frio já vem acompanhada do sentimento de desconforto, e na experiência concreta usualmente não ocorre uma distinção clara desses momentos. Isso fica evidente no modo mesmo como nos expressamos no cotidiano: quando dizemos "estou sentindo frio", já estamos, normalmente, referindo-nos simultaneamente à sensação de frio e ao incômodo que a acompanha. A unidade de todas as sensações do corpo se relaciona, além disso, com a própria ideia do corpo vivo como

5 Conforme já mencionei, um indício claro que de a diferença entre Körper e Leib não estava plenamente desenvolvida em Ideen II é o fato de Husserl utilizar, na passagem citada, apenas a expressão "Leib", apesar de tratar aqui justamente da distinção entre corpo enquanto algo próprio e corpo enquanto mera coisa física. 
pertencente a uma "alma" ${ }^{6}$, ou ego: "a alma e o ego psíquico 'têm' um corpo; há uma coisa material, de determinada natureza, que não é mera coisa material mas é um corpo (Leib)" (HUSSERL, Ideen II, §40, p. 157).

Ora, Husserl aponta aqui, em primeiro lugar, para a necessidade de distinguir aspectos relacionados a certos elementos das sensações do corpo - aqueles de natureza propriamente psíquica - da ideia de mera causalidade aos quais todos os objetos físicos estão sujeitos. Não se está negando, é claro, que também o corpo vivo seja sujeito às mesmas leis físicas dos outros objetos, como a gravidade. O que ocorre, porém, é que certos aspectos do corpo são de natureza psíquica e não propriamente física: os diversos estados "mentais", por assim dizer, não ocupam um lugar no espaço, não possuem um "peso", etc. Nesse sentido, há elementos no conjunto das sensações diversas do corpo que pertencem ao mundo das coisas "reais" apenas enquanto estados psíquicos de um ego ou "alma".

Essa é, em última instância, o fundamento mesmo da diferença entre o corpo vivo e as meras coisas físicas para Husserl. O corpo, embora seja, em determinado aspecto, exclusivamente físico e semelhante, portanto, aos demais objetos do mundo, possui também a propriedade diferencial de ser corpo animado por uma "alma" ou ego, com elementos de natureza psíquica e não material. Mas também essa diferença, tal como as anteriores, caracteriza uma diferenciação em certo sentido artificial: o corpo vivo é vivenciado de tal modo que configura um conjunto integrado de organismo cuja natureza é psicofísica ${ }^{7}$.

A esse respeito, as análises de Edith Stein seguem uma direção próxima às de Husserl, também desenvolvendo questões relacionadas às peculiaridades do corpo vivo em relação ao movimento, à vontade, à pluralidade de sensações e sentimentos e à questão da unidade psicofísica. O que ocorre, porém, é que, embora procure manter intacta

6 Por "alma", evidentemente, Husserl se refere à propriedade psíquica do corpo e não a algo sobrenatural ou religioso, valendo o mesmo no caso das obras de Stein dedicadas à fenomenologia.

7 Pode parecer, certamente, que as considerações de Husserl se mostrem excessivamente antropocêntricas, uma vez que ele se refere exclusivamente ao corpo humano apesar de desenvolver análises que, em grande parte, contemplariam os corpos vivos dos animais. Na verdade, em Ideen II, o filósofo trata de maneira mais ampla do tema, abrangendo também essa questão, sobretudo na seção dois da obra. Não caberia, porém, desenvolver uma análise nessa direção. 
a estrutura metodológica indicada por seu professor, Stein acaba por aprofundar esses temas e por estabelecer distinções conceituais que não encontramos nas obras husserlianas. Um desses aspectos é o maior detalhamento em relação ao papel dos sentimentos e sua vivência a partir do corpo vivo, o que também terá implicações importantes, como veremos adiante, em suas considerações sobre a empatia. No que diz respeito ao movimento, Stein ressalta novamente a artificialidade em tentar analisar nosso corpo desde a perspectiva de mero corpo físico:

Não é em absoluto concebível como se deve chegar a uma distinção entre os dois casos, entre o movimento das outras coisas e do meu corpo físico, ou, de modo geral, a apreensão do movimento do próprio corpo físico, enquanto se mantiver a ficção de que nosso corpo se constitui somente na percepção externa e não, caracteristicamente, como corpo vivo. [...] O corpo vivo é um objeto dado a mim em uma série de aparências que somente são variáveis dentro de limites muito estreitos [...], ele está sempre "aqui" [...]. Um corpo vivo somente percebido externamente seria sempre somente um corpo físico classificado de forma especial, singularizado, mas jamais "meu corpo vivo" (ZPE, p. 57-58).

Assim, não é apenas, como indica Husserl, que o corpo vivo tem a peculiaridade de ser um corpo "automovível", mas sim que é necessário sublinhar que essa capacidade também envolve de maneira evidente a perspectiva desde a qual o próprio movimento é vivenciado: a vivência em primeira pessoa, desde dentro do próprio corpo. A ênfase dada por Stein é relevante, pois mais uma vez sua análise tem um foco mais centrado na distinção entre corpo físico e corpo vivo, e não apenas entre "objetos físicos" em geral e corpo vivo, como faz Husserl. Ao marcar a distinção entre Körper e Leib, Stein indica que, embora a qualidade de se mover por um ato de vontade também se aplique ao corpo enquanto analisado desde fora, isso ocorre de maneira muito diferente quando ela é vivenciada em primeira pessoa: apenas por um ato de abstração podemos analisar nosso corpo como um corpo físico movente, pois na vivência concreta do movimento estamos, por assim dizer, presos na interioridade de um "aqui" e "agora" permeado de sensações às quais somente nós mesmos temos acesso direto. 
Seguindo essa mesma linha de reflexão, Stein enfatiza também o fato de que a vivência do corpo vivo envolve uma série de elementos além das sensações mais imediatas oriundas das faculdades dos sentidos. Sua análise envolve, por exemplo, o papel dos sentimentos como elemento constitutivo do corpo, de tal modo que determinada tendência sentimental pode, inclusive, interferir na qualidade dos atos de juízo, percepção e movimento: "não somente todo ato espiritual - toda alegria, aflição, toda atividade de pensamento - é lânguida e sem cor quando 'eu' me sinto triste, mas também toda ação corporal, todo movimento que executo. Está lânguido meu corpo vivo e cada uma de suas partes" (ZPE, p. 65).

O fenômeno das vivências sentimentais aponta também para a qualidade expressiva do corpo vivo. Segundo Stein, "o sentimento pede, segundo sua essência, uma expressão, e os distintos tipos de expressão são distintas possibilidades essenciais" (ZPE, p. 71). Com isso a filósofa não está dizendo, é claro, que os sentimentos necessariamente serão expressos sempre do mesmo modo, ou mesmo que sejam sempre evidentes em sua manifestação - que não possam, por exemplo, ser disfarçados e escondidos ou mesmo fingidos. Sua defesa sustenta a ideia de que, embora com diferentes possibilidades de expressão, a vivência sentimental envolve um impulso de expressividade, o qual, no mais das vezes, implica em uma reação no corpo vivo, como chorar no caso de tristeza, ou ruborizar de vergonha. A própria alternativa de reprimir a expressão do sentimento é uma reação à tal característica de tender à expressividade.

No que diz respeito às diferenças explícitas do conceito de corpo enquanto Körper e enquanto Leib, Husserl desenvolve uma análise mais detalhada somente em Krisis. Nessa obra, o filósofo afirma que “o corpo (Körper) e o corpo vivo (Leib) são, segundo a percepção, essencialmente diferentes; o corpo vivo enquanto o único corpo efetivamente perceptivo, o meu corpo vivo" (HUSSERL, Krisis, §28, p. 109 [p. 86], t.a.). Leib possui a peculiaridade de ser o corpo propriamente perceptivo porque é sempre a partir dele, enquanto corpo animado, que a percepção é possível. Na experiência concreta do mundo da vida, no mais das vezes, já nos pensamos enquanto corpo vivo.

Em uma reflexão já mais próxima às considerações de Edith Stein, Husserl reconhece que a abstração do nosso corpo enquanto 
Körper, naquilo que ele tem em comum com os demais objetos do mundo, é em certo sentido uma reflexão artificial: não vivenciamos o nosso corpo como uma coisa qualquer entre outras coisas, pois toda a experiência de contato com o mundo ocorre justamente por meio do corpo. Não é como se houvesse apenas uma diferença quantitativa no modo como nos relacionamos com o nosso corpo e com os demais corpos, não se trata apenas do fato de termos um contato distinto ou mais próximo com o corpo que nos pertence. De fato, trata-se de uma vivência qualitativamente distinta: nós somos o nosso corpo.

Nesse sentido, embora possamos, é claro, fazer reflexões puramente teóricas sobre o corpo, ou analisá-lo em termos científicos quanto ao seu funcionamento, ou pensá-lo em abstração do fato de ser o corpo de alguém, todas essas considerações são em certo sentido derivadas e secundárias em relação à experiência básica de pertencimento com o corpo vivo. Mesmo em um contexto cultural e filosófico em que domine a crença de que a verdadeira identidade do ser humano é ser uma alma e não um corpo $^{8}$, ainda que o corpo seja concebido como algo impuro e inferior à alma ou espírito, ainda assim, na vivência concreta e no mundo da vida, o corpo é tomado como algo que nos pertence em um sentido completamente diferente daquele pelo qual dizemos que os objetos nos pertencem. Análise essa, aliás, sobre a qual Stein certamente estaria de acordo, ao menos no contexto de Zum Problem der Einfühlung.

Ainda assim, a principal diferença entre as considerações de Husserl e Stein sobre o corpo está no papel da experiência de empatia para a formulação e distinção entre Leib e Körper, assim como da importância desse caráter dual da noção de corpo para o próprio conceito de empatia, uma vez que são aspectos mutuamente necessários e interligados na sua formulação, ambos também fundamentais, como ficará mais claro a seguir, para a própria constituição da subjetividade. Uma das peculiaridades das análises de Stein, como veremos, é sua ênfase no fato de que a possibilidade de entender de maneira plena a diferença entre as vivências do corpo próprio como Leib e como Körper é a própria

80 que realmente corresponde à crença religiosa professada por Husserl, de modo que o filósofo não está assumindo nenhuma posição materialista sobre esse tema. 
experiência de empatia: ao perceber o corpo do outro como análogo ao meu, e ao inferir, ainda que evidentemente sem jamais poder experienciar em primeira pessoa, que os corpos de outras pessoas são por elas vivenciados enquanto corpo vivo (embora eu os perceba inicialmente enquanto corpo físico), posso também reconhecer meu próprio corpo nessa dualidade de percepções possíveis, já que esse olhar que dirijo ao corpo alheio também pode ser dirigido ao meu próprio. Do mesmo modo, ao perceber o outro como corpo vivo e inferir o significado de uma série de fenômenos por ele manifestos, como no caso das expressões de sentimentos, posso encontrar analogia com meus próprios impulsos expressivos e mesmo compreender melhor alguns aspectos de minhas vivências.

\section{A primazia de Körper e Leib para a apreensão empática e a constituição do eu em Zum Problem der Einfühlung}

Ao entrar nas análises diretamente relacionadas com o tema da empatia e do papel do corpo na apreensão empática dos sujeitos alheios, fica ainda mais evidente a originalidade do pensamento de Edith Stein. É sabido que Husserl também chega a desenvolver a noção de empatia, sobretudo na fase tardia de seu pensamento, como na obra Meditações Cartesianas, porém com um escopo mais pontual e restrito em relação à investigação do tema por Stein ${ }^{9}$. No caso das considerações husserlianas, a empatia surge como um dos conceitos necessários para enfrentar a dificuldade em torno da superação do solipsismo. Assim, como explica Husserl, sua análise se volta ao problema da apreensão da alteridade enquanto alter-ego, do "problema do aí para mim dos outros, portanto, como tema de uma teoria transcendental da experiência do que me é alheio, da chamada empatia" (HUSSERL, Cartesianische Meditationen, §43, p. 124 [p. 130]).

\footnotetext{
É claro que se a intenção fosse ampliar a análise para as obras ainda mais recentes do filósofo, editadas a partir de manuscritos inacabados e apontamentos de aula, haveria outras questões a serem desenvolvidas. Porém, como o foco central são as obras produzidas a partir de manuscritos mais "robustos" e sem uma separação temporal tão grande em relação a Zum Problem der Einfühlung, ficamos com a bibliografia husserliana mais clássica, o que também nos auxilia a não desviar o foco da fenomenologia de Edith Stein. Para um maior aprofundamento comparativo entre os dois autores, ver Jardine (2015).
} 
Marianne Sawicki resume o que entende ser a principal diferença entre as considerações sobre o conceito de empatia em Husserl e Stein do seguinte modo: "Para ele [Husserl], 'experiência de outros indivíduos' se refere ao experienciar deles do mundo. Stein, no entanto, está interessada no experienciar próprio de outras pessoas enquanto seres humanos; isto é, de como as pessoas estão mutuamente disponíveis para serem compreendidas" (SAWICKI, 1997, p. 2). Estou em parte de acordo com essa interpretação, no sentido de que de fato Stein amplia o escopo das análises sobre a empatia ao investigar a experiência de mútua compreensão, com tudo que isso envolve: reconhecimento da outra pessoa em seus aspectos físicos e psíquicos, verificação de como isso interfere no próprio entendimento do eu, etc. Mas acredito que também Husserl tem uma preocupação com o reconhecimento mútuo, ainda que mais restrita, e não apenas com uma análise unilateral, como sugere Sawicki ${ }^{10}$. Conforme já foi indicado na exposição comparativa em relação ao conceito de corpo, acredito que uma das principais diferenças, além da já demonstrada abrangência do conceito, é a ênfase dada por Stein na importância que a apreensão do outro em sua corporeidade tem para a compreensão do próprio corpo e, como consequência, também para o entendimento do eu em sua plenitude.

Para que isso fique mais claro, é preciso investigar como a filósofa introduz a experiência de empatia como surgindo, justamente, da percepção do sujeito alheio como algo que não pode ser mero corpo físico. Stein explicita que a experiência de outros sujeitos surge de uma

10 Embora não caiba aqui um aprofundamento dessa questão, remeto, para exemplificar a validade de tal interpretação, a algumas passagens de Cartesianische Meditationen, por exemplo: "Na apresentação do outro, os sistemas sintéticos são os mesmos, com todos os seus modos de doação que nelas se tornam efetivos [...]. Não tenho primeiro uma segunda esfera original apresentada, com uma segunda natureza, para depois me perguntar como faço para poder apreender ambas as esferas como modos de aparição da mesma natureza objetiva. Ao contrário, através da própria apresentação que é para ela cofuncionante [...], está já necessariamente produzido o sentido identitário da minha natureza primordial e da outra natureza presentificada. É, portanto, com inteira justificação que ela se chama percepção do alheio e, subsequentemente, percepção do mundo objetivo, percepção de que o outro olha para o mesmo que eu, etc., se bem que esta percepção se desenrole exclusivamente no interior da minha esfera de propriedade" (HUSSERL, Cartesianische Meditationen, §55, p. 152-153 [p. 161-162]); "[as outras culturas] são acessíveis, a mim e aos que participam da minha cultura, numa espécie de experiência do alheio e em um tipo de empatia na humanidade alheia e na sua cultura" (HUSSERL, Cartesianische Meditationen, §58, p. 161 [p. 172]). 
vivência que denomina de "cooriginaridade" (Konoriginarität): não se trata de uma experiência originária, pois essa só é dada diretamente, nas "vivências próprias" imediatas e atualmente presentes, como o experienciar direto, por exemplo, do movimento do próprio corpo a partir de um ato de vontade. $\mathrm{Na}$ experiência cooriginária, o outro é apreendido em certo sentido de maneira análoga: reconheço que o modo como ele se apresenta não é idêntico à maneira de apresentação dos demais objetos do mundo. É possível, claro, conceber os sujeitos alheios enquanto meros objetos físicos, quando por exemplo fazemos considerações sobre o peso de seus corpos, ou sobre o espaço que ocupam, etc. Mas essas seriam considerações secundárias e particulares, em certo sentido derivadas da experiência mais imediata. De modo direto, o vivenciar de outros sujeitos já envolve essa percepção de se tratar de um sujeito semelhante a mim, e, portanto, "o corpo alheio é 'visto' como corpo vivo" (ZPE, p. 75).

Porém, é evidente que a experiência de conceber os demais como portadores de corpos vivos e não meros corpos físicos não é direta: não tenho como assumir o lugar do outro para de fato vivenciar de maneira originária tal experiência. Justamente por isso, entra aqui a peculiaridade da "via de mão dupla" que é o ato de empatia: como não há vivência direta dos corpos alheios como corpos vivos, preciso não apenas projetar, a partir da minha própria prática corporal, que os demais sujeitos vivenciam seus corpos como corpos vivos, mas também preciso abstrair da minha experiência imediata de me entender como corpo vivo para me conceber como um corpo físico, como um corpo que pode ser visto desde fora.

Através de tal atividade, como explica Stein, posso gerar uma empatia em relação às possíveis sensações dos corpos vivos alheios, por definição jamais acessíveis originariamente: a "possibilidade da empatia de sensação [...] está garantida pela compreensão do corpo vivo próprio como corpo físico, e do corpo físico próprio como corpo vivo, em virtude da fusão de percepção externa e percepção corporal" (ZPE, p. 77). Ou seja: é por poder projetar meu próprio corpo com algo que pode ser percebido desde fora como corpo físico que posso encontrar uma analogia em relação à percepção dos corpos alheios e 
entendê-los como corpos vivos. Stein explicita como se dá essa passagem e suas implicações para a percepção espacial:

O corpo do outro indivíduo, enquanto mero corpo físico, é uma coisa espacial como as demais e está dado em certo lugar do espaço, a certa distância de mim, dentro da orientação espacial, e em determinadas relações espaciais com o mundo espacial restante. Então, à medida que o compreendo enquanto corpo vivo sensível, transferindo-me a ele de modo empático, adquiro uma nova imagem do mundo espacial e um novo ponto zero de orientação (ZPE, p. 79).

Assim, enquanto observo o corpo dos demais sujeitos enquanto meros corpo físicos não projeto neles nenhuma reflexão de analogia sobre como devem ser suas vivências enquanto corpos vivos, e sua relação espacial é a mesma de qualquer objeto no mundo. Porém, à medida que a compreensão faz a passagem para a apreensão empática, os corpos alheios passam a ser vistos como corpos vivos e, posso, portanto, imaginar sua vivência interna a partir da qual aquele lugar onde ele está é, para esse outro sujeito, o ponto zero de orientação, o local desde o qual se dá sua relação espacial com os demais objetos - incluindo, nesse caso, meu próprio corpo que é visto por ele desde sua perspectiva.

Com isso ocorre um fenômeno interessante, que seria, aliás, um dos aspectos mais relevantes da experiência empática: a projeção da "imagem alheia do mundo" tem a função de gerar uma "modificação" na minha própria concepção. Segundo Edith Stein: a "imagem do mundo que eu empatizo como sendo do outro não somente é uma modificação da minha em função da orientação distinta, mas também varia de acordo com como se concebe a condição de seu corpo vivo" (ZPE, p. 80). Ou seja, com a experiência empática de vislumbrar como é o mundo desde a perspectiva do outro, projeto olhares que não estariam dados do meu ponto de vista atual. E, assim, "aqui se mostra a possibilidade do enriquecimento da própria imagem do mundo através da imagem dos outros, e a relevância da empatia para a experiência do mundo externo real"' (ZPE, p. 80).

Mas Stein vai mais adiante na sua ênfase em relação aos resultados da experiência empática: ela não apenas influencia e modifica a 
visão de si e do mundo, como é, também, "condição de possibilidade da constituição do indivíduo próprio", e isso justamente a partir da maneira como a vivência de empatia interfere na concepção da própria corporeidade. Assim, como já havia sido mencionado anteriormente, não é apenas que a análise do corpo alheio seja fundamento para a empatia, mas também que a experiência empática determina uma alteração na concepção da própria corporeidade. Nas palavras de Edith Stein:

A partir do ponto zero de orientação obtido na empatia tenho que considerar meu próprio ponto zero como um ponto do espaço entre muitos, e não mais como um ponto zero. E assim, por isso, e apenas por isso, aprendo a ver ao meu corpo vivo enquanto um corpo físico como os demais, embora na experiência originária me seja dado somente como corpo vivo [...]. Na "empatia reiterada" [iterierter Einfühlung] compreendo de novo aquele corpo físico como corpo vivo, e somente assim estou dado a mim mesmo em sentido pleno como indivíduo psicofísico para o qual é constitutivo o estar fundado em um corpo. Essa empatia reiterada é condição de possibilidade de aquele dar-se a si mesmo ao modo de imagem nas lembranças e na fantasia [...]. Quando me vejo na copa de uma árvore em uma recordação de infância [...] me vejo como outro, ou como o outro me vê, e isso é algo possibilitado pela empatia (ZPE, p. 80-81).

Assim, a tese que Stein sustenta é que a própria possibilidade de conceber a si mesmo desde fora, enquanto corpo físico como os demais, é gerada pela experiência de empatia. É importante notar que apesar de a análise fenomenológica explicitar suas descrições passo a passo, essas apreensões de vivências não se dão, é claro, em uma ordem temporal definida - por exemplo, primeiro conceber o outro em experiência empática para, daí sim, passar a ver-me enquanto sujeito entre os demais e daí a imaginar minha figura desde fora. Evidentemente, são essas experiências naturais da vivência cotidiana, já incorporadas em nossa concepção de mundo, que geram tais fenômenos agora analisados em seus aspectos constitutivos na análise fenomenológica descritiva.

E assim, a partir de tal investigação fenomenológica, é possível perceber que a vivência natural de si e da própria corporeidade desde a perspectiva imediata interna, desde o ponto de vista do corpo vivo, pode ser modificada ao vislumbrar a si mesmo desde uma outra 
perspectiva possível - desde um olhar alheio, externo - e, portanto, a partir de uma visão empática de outro corpo. Esse processo envolve justamente o que Stein conceitua na passagem citada de "empatia reiterada": ao conceber a experiência empática que o outro tem de mim, posso me imaginar desde fora, a partir de tal vivência que não me é possível enquanto experiência originária e direta.

Desse modo, ainda que, conforme mencionado inicialmente, Edith Stein parta da intenção de utilizar do método fenomenológico para a análise do fenômeno da empatia em particular, sem com isso ter a princípio qualquer intenção de originalidade em relação às considerações clássicas da fenomenologia, o fato é que a filósofa acaba por abrir caminho para todo um campo novo de considerações fenomenológicas que viriam, depois, a se estabelecer como algumas das áreas mais relevantes para tais estudos. Que Stein atribua à experiência de empatia, como vimos, um papel fundamental na própria constituição do eu como concretamente vivenciado, em certa medida a afasta de Husserl, mas a aproxima dos fenomenólogos das gerações seguintes, sobretudo daqueles dedicados a encontrar um lugar para o conceito de corpo nos estudos filosóficos.

\section{Referências}

DEPRAZ, N. Transcendance et incarnation. Le statut de l'intersubjectivité comme altérité à soi chez Husserl. Paris: Vrin (Histoire de la philosophie), 1995.

HUSSERL, E. Husserliana 1. Cartesianische Meditationen und Pariser Vorträge. Ed. S. Strasser. Den Haag: Martinus Nijhoff, 1973 [1950]. [Meditações Cartesianas e Conferências de Paris. Rio de Janeiro: Forense Universitária, 2012].

HUSSERL, E. Husserliana 4. Ideen zu einer reinen Phänomenologie und phänomenologischen Philosophie. Zweites Buch. Phänomenologische Untersuchungen zur Konstitution. Ed. M. Biemel. The Hague: Martinus Nijhoff, 1952. 
HUSSERL, E. Husserliana 6. Die Krisis der europäischen Wissenschaften und die transzendentale Phänomenologie. Eine Einleitung in diephänomenologische Philosophie. Ed. W. Biemel. The Hague: Martinus Nijhoff, 1962 [1954]. [A crise das ciências europeias e a fenomenologia transcendental. São Paulo: Forense Universitária, 2012].

JARDINE, J. A. Husserl and Stein on the Phenomenology of Empathy: Perception and Explication. Synthesis Philosophica, v. 29, n. 2, p. 273-288, 2015.

SZANTO, T.; JARDINE, J. A. Empathy in the Phenomenological Tradition. In: MAIBOM, H. L. (Ed.). The Routledge Handbook of Philosophy of Empathy. London: Routledge, 2017. c. 8, p. 86-97.

SAWICKI, M. Body, Text and Science: The Literacy of Investigative Practices and the Phenomenology of Edith Stein. Dordrecht: Kluwer, 1997.

STEIN, E. Zum Problem der Einfühlung. Freiburg/Basel/Wien: Herder, 2008.

Recebido: 23/09/2017

Received: 09/23/2017

Aprovado: 06/10/2017

Approved: 10/06/2017 